\title{
DESEMPENHO DE UM CONJUNTO TRATOR-SEMEADORA-ADUBADORA EM FUNÇÃO DO MECANISMO SULCADOR E VELOCIDADE DE DESLOCAMENTO
}

\author{
Raquel Santana Milagres ${ }^{1}$, Marconi Ribeiro Furtado Júnior ${ }^{2}$, Anderson Candido da Silva ${ }^{3}$, Jefférson Machado \\ Fontes ${ }^{4}$
}

\section{RESUMO}

Objetivou-se, com este trabalho, avaliar as variáveis velocidade de deslocamento, força, potência requerida para tração da semeadora-adubadora e patinagem das rodas motrizes do trator em função do mecanismo dosador e velocidade de deslocamento. Foram utilizadas cinco velocidades de deslocamento obtidas em função dos escalonamentos de marchas, das variações nas rotações do eixo do motor do trator e de duas configurações de montagem de linha de plantio. O experimento foi realizado no delineamento em blocos ao acaso com três repetições. Pode-se concluir que a variável força requerida para tração da semeadora-adubadora mostrou-se constante e independente da velocidade de deslocamento do conjunto mecanizado, já para demanda de potência, a configuração com discos defasados apresentou valores superiores ao mecanismo tipo facão em todas as velocidades e rotações do eixo do motor avaliadas.

Palavras-chave: desempenho, semeadura direta, semeadora, trator

\section{ABSTRACT \\ PERFORMANCE OF A TRACTOR-SEEDER SET IN FUNCTION OF FURROW OPENING MECHANISM AND TRAVEL SPEED}

The objective of this work was to evaluate the variables of displacement speed, force and power required to pull the seeder and tractor driving wheel slip. Five displacement speeds were obtained in function of the gear variations, changes in rotation of the tractor's axis and two configurations of planting row mountings. The experiment was conducted in randomized blocks with three replicates. It could be concluded that the variable force required for planting was constant and independent of the displacement speed of the mechanized set. For power demand, the configuration in unbalanced double discs presented higher values than the knife mechanism at all speeds and rotations of the tractor's axis evaluated.

Keywords: performance, no-tillage, seeder, tractor

Recebido para publicação em 16/12/2014. Aprovado em 23/02/2015.

1 - Estudante de graduação, Agronomia/UFV, Viçosa - MG, raquelsmilagres@yahoo.com.br

2 - Eng. ${ }^{\circ}$ Agrônomo, Doutorando em Mecanização Agrícola, DEA/UFV, Viçosa - MG, marconi.furtado@gmail.com

3 - Eng. ${ }^{\circ}$ Agrônomo, Mestrando em Mecanização Agrícola, DEA/UFV, Viçosa - MG, andersoncandido@hotmail.com

4 - Eng. ${ }^{\circ}$ Mecânico, Doutor em Mecanização Agrícola, DEA/UFV, Viçosa - MG, jfontes@ufv.br 


\section{INTRODUÇÃO}

O sistema plantio direto é uma prática conservacionista de preparo do solo e de semeadura que se baseia em três princípios básicos: revolvimento apenas na linha de plantio, manutenção dos resíduos vegetais da cultura antecessora sobre a superfície do solo e rotatividade de culturas.

As semeadoras-adubadoras utilizam mecanismos sulcadores para promover aberturas de sulcos e possibilitar a deposição, no solo, das sementes e do adubo em profundidades adequadas para cada cultura, propiciando condições ideais de germinação e desenvolvimento inicial de plantas.

A consolidação do sistema de semeadura direta trás grandes benefícios ao meio ambiente e, também, é notável a redução dos custos de produção devido a desnecessidade das operações como aração, subsolagem, escarificação e gradagem. Porém, nesse sistema, se têm muitos problemas relacionados à compactação das camadas superficiais em função do tráfego de máquinas. A solução encontrada pelos agricultores tem sido a substituição, na semeadora-adubadora, do sulcador disco duplo pela haste sulcadora que atua em profundidades superiores (PALMA et. al., 2010).

Considerando que as condições para o desenvolvimento das culturas dependem do tipo de solo e do teor de água, entre outras variáveis, fica evidente que o projeto de mecanismo sulcador não pode ser limitado a um único tipo capaz de ser usado para qualquer situação (MION; BENEZ, 2008).

O uso do sistema de abertura de sulcos para deposição de fertilizante do tipo haste sulcadora aumenta as exigências de força de tração, o consumo de combustível (horário e específico) e o índice de patinagem em relação ao sistema de abertura de sulcos do tipo discos duplo (SANTOS et al., 2008), porém Mion e Benez (2008) verificaram que a haste promove maior mobilização de solo.

Levien et al. (2011) concluíram que o uso de sulcador tipo haste implica em maior demanda de esforço de tração, patinagem do trator e consumo de combustível por área trabalhada e não influenciaram o volume de solo mobilizado, a população de plantas e a produtividade de grãos do milho, em relação à operação realizada com o uso de sulcador de adubo de discos duplos.

Sendo assim, objetivou-se avaliar a demanda de potência de um conjunto mecanizado, composto por trator agrícola e semeadora-adubadora, no sistema de plantio direto em função mecanismos sulcadores, da velocidade de deslocamento e a rotação do eixo do motor.

\section{MATERIAIS E MÉTODOS}

Este trabalho foi realizado em área experimental da Universidade Federal de Viçosa, localizada no Município de Viçosa, região da Zona da Mata do Estado de Minas Gerais, com altitude média de $723 \mathrm{~m}$ e coordenadas geográficas de $20^{\circ} 46^{\prime} 42,2^{\prime \prime}$ de latitude sul e $42^{\circ} 51^{\prime} 52,9$ " de longitude oeste, em um Latossolo Vermelho-Amarelo Distrófico com textura classificada com muito argilosa (62\% de argila, $8 \%$ de silte e $30 \%$ de areia).

A área experimental encontrava-se com vegetação espontânea composta por plantas daninhas anuais, principalmente capim-braquiária (Brachiaria decumbens), guaxuma (Sida spp.), trapoeraba (Commelina benghalensis), caruru (Amaranthus hibridus) e picão-preto (Bidens pilosa), além de reduzida quantidade de restos culturais de milho. Essa vegetação foi suprimida com o auxílio de conjunto mecanizado composto por roçadora e trator agrícola, 10 dias antes da data de instalação do experimento, em uma única operação de corte. Os restos vegetais dessa atividade foram deixados espalhados naturalmente sobre o solo.

O solo apresentou densidade de $1,25 \mathrm{~g} \mathrm{~cm}^{-3} \mathrm{e}$ $\mathrm{o}$ teor de água de $0,17 \mathrm{~g} \mathrm{~g}^{-1}$. Essas propriedades do solo foram determinadas pelos métodos do anel volumétrico e gravimétrico-padrão, de acordo com Embrapa (2011).

A resistência do solo à penetração foi medida com base na norma técnica ASAE S313.3 (2009), utilizando-se um penetrômetro eletrônico da marca DLG, modelo PNT-2000, na faixa de 0 a $0,3 \mathrm{~m}$ de profundidade (Figura 1).

\section{REVENG}




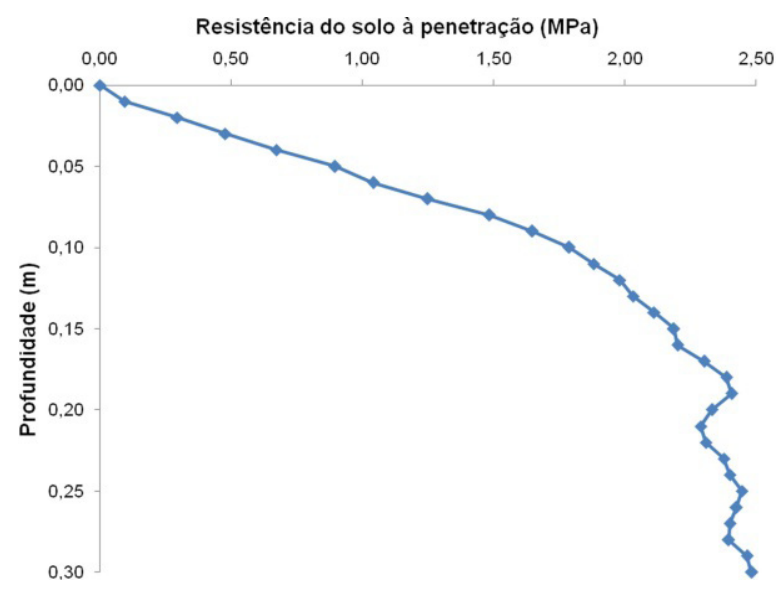

Figura 1. Resistência do solo à penetração em função da profundidade.

Foi utilizada a semeadora-adubadora da marca Seed-Max, Modelo PC 2123, capacidade para montagem de até três linhas de plantio; dosador de sementes tipo disco horizontal perfurado; e dosador de adubo do tipo rosca helicoidal.

Foram avaliadas duas configurações de montagem da linha de plantio. A primeira foi denominada versão "A", que era composta pelos seguintes mecanismos: disco de corte, disco duplo defasado no sistema de deposição de adubo, disco duplo defasado no sistema de deposição de sementes e rodas de cobertura e controle de profundidade. A segunda denominada "B", o mecanismo sulcador tipo disco duplo defasado utilizado no sistema de deposição de adubo foi substituído por outro do tipo facão com ponteira removível e regulagem individual de profundidade e de ângulo de ataque. Na Figura 2 são ilustradas, respectivamente, as versões de montagem " $\mathrm{A}$ " $\mathrm{e}$ "B" da linha de plantio.

$\mathrm{Na}$ avaliação do desempenho do conjunto mecanizado foram utilizados dois tratores, sendo avaliado um trator Massey Ferguson do Brasil S.A., modelo MF 265 , versão 4 x 2, com tração dianteira auxiliar (TDA). Esse trator possuía 2.590 $\mathrm{kg}$ de massa sem lastro e $3.743 \mathrm{~kg}$ com lastro máximo. A potência nominal no motor era de $47,8 \mathrm{~kW}(65 \mathrm{cv})$ a $2.200 \mathrm{rpm}$ e o torque máximo de $225,4 \mathrm{mN}$ (23 mkgf) a 1.300 rpm. A distância entre eixos era de 2,14 metros e utilizava rodado simples com pneus diagonais, sendo os dianteiros 12.4-24R1 e os traseiros 18.4-30R1. O outro trator o qual a semeadora-adubadora foi integralmente acoplada ao sistema de levante hidráulico, foi um modelo John Deere, modelo 5705, 4 x 2, com tração dianteira auxiliar (TDA), potência nominal no motor de $62 \mathrm{~kW}(85 \mathrm{cv})$ a $2.400 \mathrm{rpm}$, torque máximo de $330 \mathrm{mN}$ a $1.600 \mathrm{rpm}$ e massa de 2.790 $\mathrm{kg}$ sem lastro. $\mathrm{O}$ trator estava lastrado com quatro pesos frontais de $50 \mathrm{~kg}$, rodados simples, pneus dianteiros 12.4-24R1 e traseiros 18.4-30R1.

Durante os ensaios, a caixa de câmbio do trator fabricado pela John Deere (trator 2) foi mantida em neutro e os mecanismos sulcadores da semeadoraadubadora em operação.

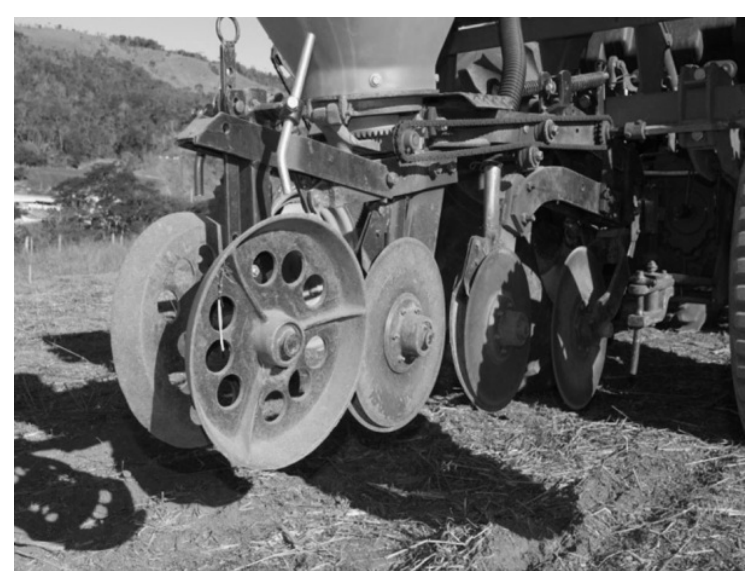

(A)

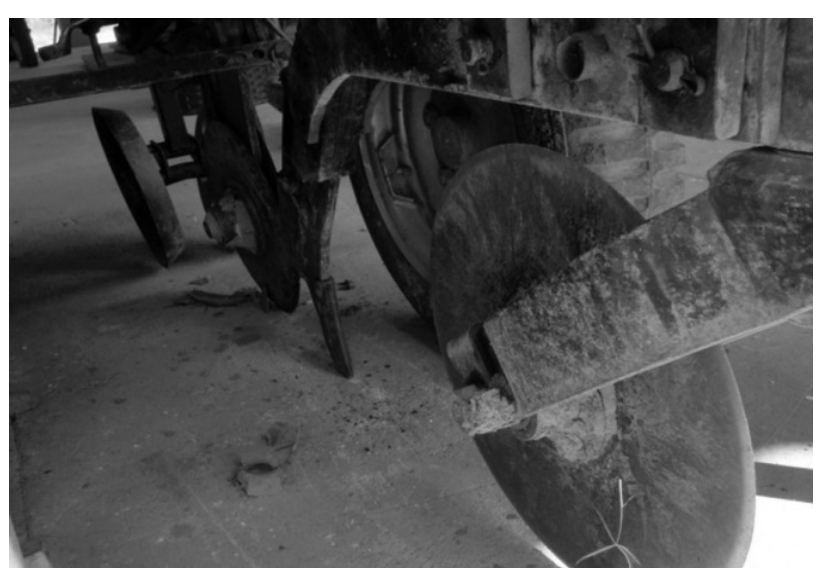

(B)

Figura 2. (A) Configuração "A" de montagem da linha de plantio (disco duplo defasado); (B) Configuração "B" de montagem da linha de plantio (facão). 
Quadro 1. Velocidades médias de deslocamento do conjunto mecanizado.

\begin{tabular}{|c|c|c|c|c|c|c|c|}
\hline \multirow{4}{*}{ Marcha } & \multirow{4}{*}{ Rotação } & \multicolumn{6}{|c|}{ Semeadora-adubadora } \\
\hline & & \multirow{2}{*}{\multicolumn{2}{|c|}{ Posição de transporte }} & \multicolumn{4}{|c|}{ Efetivamente em operação } \\
\hline & & & & \multicolumn{2}{|c|}{ Configuração "A" } & \multicolumn{2}{|c|}{ Configuração "B" } \\
\hline & & Sigla & $\begin{array}{l}\text { Velocidade } \\
\left(\mathrm{km} \mathrm{h}^{-1}\right)\end{array}$ & Sigla & $\begin{array}{l}\text { Velocidade } \\
\left(\mathrm{km} \mathrm{h}^{-1}\right)\end{array}$ & Identificação & $\begin{array}{l}\text { Velocidade } \\
\quad\left(\mathrm{km} \mathrm{h}^{-1}\right)\end{array}$ \\
\hline 2RA & 1800 & $\mathrm{~V}_{\mathrm{M} 1}$ & 3,95 & $\mathrm{~V}_{\mathrm{M} 1 \mathrm{~A}}$ & 3,72 & $\mathrm{~V}_{\mathrm{M} 1 \mathrm{~B}}$ & 3,68 \\
\hline $3 R B$ & 1600 & $\mathrm{~V}_{\mathrm{M} 2}$ & 5,16 & $\mathrm{~V}_{\mathrm{M} 2 \mathrm{~A}}$ & 4,86 & $\mathrm{~V}_{\mathrm{M} 2 \mathrm{~B}}$ & 4,77 \\
\hline 3RA & 1600 & $\mathrm{~V}_{\mathrm{M} 3}$ & 6,69 & $\mathrm{~V}_{\mathrm{M} 3 \mathrm{~A}}$ & 6,58 & $\mathrm{~V}_{\mathrm{M} 3 \mathrm{~B}}$ & 5,67 \\
\hline 3RA & 1800 & $\mathrm{~V}_{\mathrm{M} 4}$ & 7,14 & $\mathrm{~V}_{\mathrm{M} 4 \mathrm{~A}}$ & 6,82 & $\mathrm{~V}_{\mathrm{M} 4 \mathrm{~B}}$ & 6,13 \\
\hline $1 \mathrm{SB}$ & 1700 & $\mathrm{~V}_{\mathrm{M} 5}$ & 8,23 & $\mathrm{~V}_{\mathrm{M} 5 \mathrm{~A}}$ & 7,68 & $\mathrm{~V}_{\mathrm{M} 5 \mathrm{~B}}$ & 6,89 \\
\hline
\end{tabular}

No Quadro 1 são apresentadas as denominações das velocidades de deslocamento do conjunto mecanizado para as cinco combinações de marcha e rotação do eixo do motor para a "configuração".

O tempo consumido para percorrer toda a extensão das unidades experimentais que tinham $20 \mathrm{~m}$ de comprimento, foi medido com o auxílio de um cronômetro.

Para medir as forças requeridas para tração do conjunto mecanizado e de resistência ao deslocamento oferecida pelo trator 2 , instalouse entre os tratores um dinamômetro com célula de carga marca KRATOS, modelo IK-14 ${ }^{\mathrm{a}}$, com capacidade para $50 \mathrm{kN}$. Posteriormente, efetuou-se a média aritmética dos valores obtidos experimentalmente.

A força requerida para tração da semeadoraadubadora foi determinada empiricamente pela diferença entre a força requerida para tração do conjunto mecanizado e a força de resistência ao deslocamento oferecida pelo trator 2, por meio da equação 1 .

$\mathrm{F}_{\mathrm{TS}}=\mathrm{F}_{\mathrm{TC}}-\mathrm{F}_{\mathrm{TT}}$

em que,

$\mathrm{F}_{\mathrm{TS}}=$ força requerida para tração da semeadoraadubadora $(\mathrm{kN})$;

$\mathrm{F}_{\mathrm{TC}}=$ força requerida para tração do conjunto mecanizado $(\mathrm{kN})$; e

$\mathrm{F}_{\mathrm{TT}}=$ força de resistência ao deslocamento oferecida pelo trator $2(\mathrm{kN})$.
A potência requerida para tracionar a semeadora-adubadora foi determinada para cada configuração de montagem da linha de plantio por meio da equação 2 , com base nas médias obtidas experimentalmente para a força de tração e velocidade de deslocamento do conjunto mecanizado.

$\mathrm{P}_{\mathrm{SM}}=\frac{\mathrm{F}_{\mathrm{SM}} \mathrm{V}_{\mathrm{M}}}{3,6}$

em que,

$\mathrm{P}_{\mathrm{SM}}=$ potência requerida para tração da semeadoraadubadora $(\mathrm{kW})$;

$\mathrm{F}_{\mathrm{SM}}=$ força média requerida para tração da semeadora-adubadora $(\mathrm{kN})$;

$\mathrm{V}_{\mathrm{M}}=$ velocidade média de deslocamento $\left(\mathrm{km} \mathrm{h}^{-1}\right)$; e $3,6=$ constante utilizada para transformação de unidades.

A patinagem das rodas motrizes do trator utilizado como fonte de potência foi calculada com base nos dados obtidos experimentalmente nas duas configurações de montagem da linha de plantio.

Os ensaios foram realizados com a semeadoraadubadora posicionada em duas condições distintas. Na primeira, a semeadora-adubadora foi acoplada ao trator e mantida na posição de transporte. Essa condição foi considerada "sem carga". Na segunda,

\section{REVENG \\ 143-153p.}

ENGENHARIA NA AGRICULTURA, VIÇOSA - MG, V.23 N.2, MARÇO / ABRIL 2015 
considerada "com carga", os elementos ativos que equipavam a linha de plantio foram colocados e mantidos em operação.

Durante o percurso do conjunto mecanizado na unidade experimental, aferiu-se o número de voltas dadas pelas rodas motrizes em torno de seu eixo. Os resultados das duas condições, com e sem carga, foram registrados em uma planilha e, posteriormente, utilizados para determinar a patinagem, por meio da equação 3 .

$\mathrm{P}_{\mathrm{T}}=\frac{\mathrm{N}_{\mathrm{vcc}}-\mathrm{N}_{\mathrm{vsc}}}{\mathrm{N}_{\mathrm{vcc}}}$

em que,

$\mathrm{P}_{\mathrm{T}}=$ patinagem das rodas motrizes (decimal);

$\mathrm{N}_{\mathrm{vcc}}$ = número de voltas das rodas motrizes, com carga (adimensional); e

$\mathrm{N}_{\mathrm{vsc}}$ = número de voltas das rodas motrizes, sem carga (adimensional).

O experimento foi conduzido no delineamento em blocos ao acaso com três repetições. Foram utilizadas cinco velocidades de deslocamento e duas configurações de montagem de linha de plantio, totalizando 10 tratamentos e 30 unidades experimentais. As velocidades de deslocamento foram obtidas por meio de mudanças de marchas e alterações nas rotações do eixo do motor. Já as variações na configuração de montagem da linha de plantio são decorrentes da utilização de diferentes tipos de mecanismo sulcador no sistema de deposição de adubos da semeadora-adubadora.

Os resultados do experimento foram submetidos à análise de regressão e os modelos, escolhidos com base na significância dos coeficientes de regressão, utilizando-se o teste " $\mathrm{t}$ " e adotando-se o nível de $5 \%$ de probabilidade, bem como no coeficiente de determinação $\left(\mathrm{R}^{2}\right)$. Para realizar a análise estatística, utilizou-se o programa computacional SAEG 9.1.

\section{RESULTADOS E DISCUSSÃO}

Nos ensaios realizados com a semeadoraadubadora utilizando o mecanismo sulcador tipo disco duplo defasado no sistema de deposição de adubos (Configuração " $A$ "), a velocidade de deslocamento do conjunto mecanizado não influenciou a força requerida para tração e, sim, quando esse mecanismo (disco duplo defasado) foi substituído por outro do tipo facão (Configuração "B").

Para a configuração da montagem da linha de plantio "A", o modelo de regressão ajustado para a variável em estudo mostrou-se não significativo. Por essa razão, foi representado pela equação da reta constituída por uma constante cujo valor correspondia à média aritmética dos valores da força requerida para tração da semeadora-adubadora, obtidos experimentalmente nas cinco velocidades de deslocamento do conjunto mecanizado. A equação 4 representa esse modelo.

$$
\mathrm{F}_{\mathrm{SMA}}=3,432
$$

em que,

$\mathrm{F}_{\mathrm{SMA}}=$ Força média requerida para tração da semeadora-adubadora, na Configuração " $\mathrm{A}$ ” ( $\mathrm{kN})$.

Para a configuração de montagem da linha de plantio "B", observou-se que o modelo de regressão ajustado para a variável em estudo apresentou comportamento linear crescente com o aumento da velocidade de deslocamento e coeficiente de determinação $\left(\mathrm{r}^{2}\right)$ de 0,5183 . A equação 5 representa o modelo de regressão ajustado para essa configuração.

$\mathrm{F}_{\mathrm{SMB}}=-0,0563+1,1869 \mathrm{~V}_{\mathrm{MB}}$

em que,

$\mathrm{F}_{\mathrm{SMB}}=$ Força média requerida para tração da semeadora-adubadora, na Configuração " $\mathrm{B}$ " $(\mathrm{kN})$; e $\mathrm{V}_{\mathrm{MB}}=$ Velocidade média de deslocamento do conjunto mecanizado, com a semeadora-adubadora montada na Configuração " $\mathrm{B}$ " $\left(\mathrm{km} \mathrm{h}^{-1}\right)$.

O coeficiente de determinação $\left(\mathrm{r}^{2}\right)$ obtido para esse modelo de regressão permitiu observar que $51,83 \%$ da variação ocorrida na força requerida para tração da semeadora-adubadora, utilizando uma linha de plantio montada na Configuração "B", pode ser explicada pela alteração na velocidade de deslocamento do conjunto mecanizado. 
Na Figura 3 é mostrado o comportamento dessa variável em função da velocidade de deslocamento do conjunto mecanizado para as duas configurações de montagem da linha de plantio.

Observa-se, na Figura 3, que o conjunto mecanizado operando com a semeadora-adubadora montada na Configuração "A" apresentou comportamento linear de valor constante igual a 3,432 kN, sugerindo independência entre as variáveis. Nessas condições, constatou-se que as velocidades de deslocamento do conjunto mecanizado compreendidas no intervalo de 3,72 $\mathrm{km} \mathrm{h}^{-1}$ a 7,68 $\mathrm{km} \mathrm{h}^{-1}$ não influenciaram as forças requeridas para tração da semeadora-adubadora, quando esta utilizou o mecanismo sulcador tipo disco duplo defasado no sistema de deposição de adubo.

$\mathrm{Na}$ semeadora-adubadora montada na Configuração "B", observou-se relacionamento positivo entre as variáveis com comportamento linear crescente à taxa de 1,1869 por unidade de velocidade, ou seja, para cada incremento de 1,0 $\mathrm{km} \mathrm{h}^{-1}$ na velocidade média de deslocamento do conjunto mecanizado, a força média requerida para tração da semeadora-adubadora aumentou em
$1,1869 \mathrm{kN}$ por linha de plantio. Observou-se ainda, nessa configuração de montagem, que a menor velocidade de deslocamento $\left(3,68 \mathrm{~km} \mathrm{~h}^{-1}\right)$ foi a que requereu a menor força de tração por linha de plantio $(4,311 \mathrm{kN})$ e a maior velocidade $(6,89 \mathrm{~km}$ $\left.\mathrm{h}^{-1}\right)$, a que exigiu a maior força de tração $(8,121 \mathrm{kN})$, resultando numa variação percentual de 188,38\% para mais nos valores da variável dependente (força requerida para tração da semeadora-adubadora). Pode-se destacar também, nessa configuração de montagem da linha de plantio, a constatação de que, quanto maior a velocidade de deslocamento, maior a força requerida para tração da semeadoraadubadora.

Ao comparar os resultados das duas configurações de montagem da linha de plantio, observou-se que a configuração cujo mecanismo sulcador era do tipo facão requereu maior força para tração da semeadora-adubadora que a configuração equipada com o disco duplo defasado, em todas as velocidades de deslocamento. Foram constatados aumentos na exigência da força de tração de $27,0 \%$ e $136,6 \%$, nas velocidades de $3,72 \mathrm{~km} \mathrm{~h}^{-1}$ e $6,89 \mathrm{~km}$ $\mathrm{h}^{-1}$, respectivamente. Esses aumentos mostraram

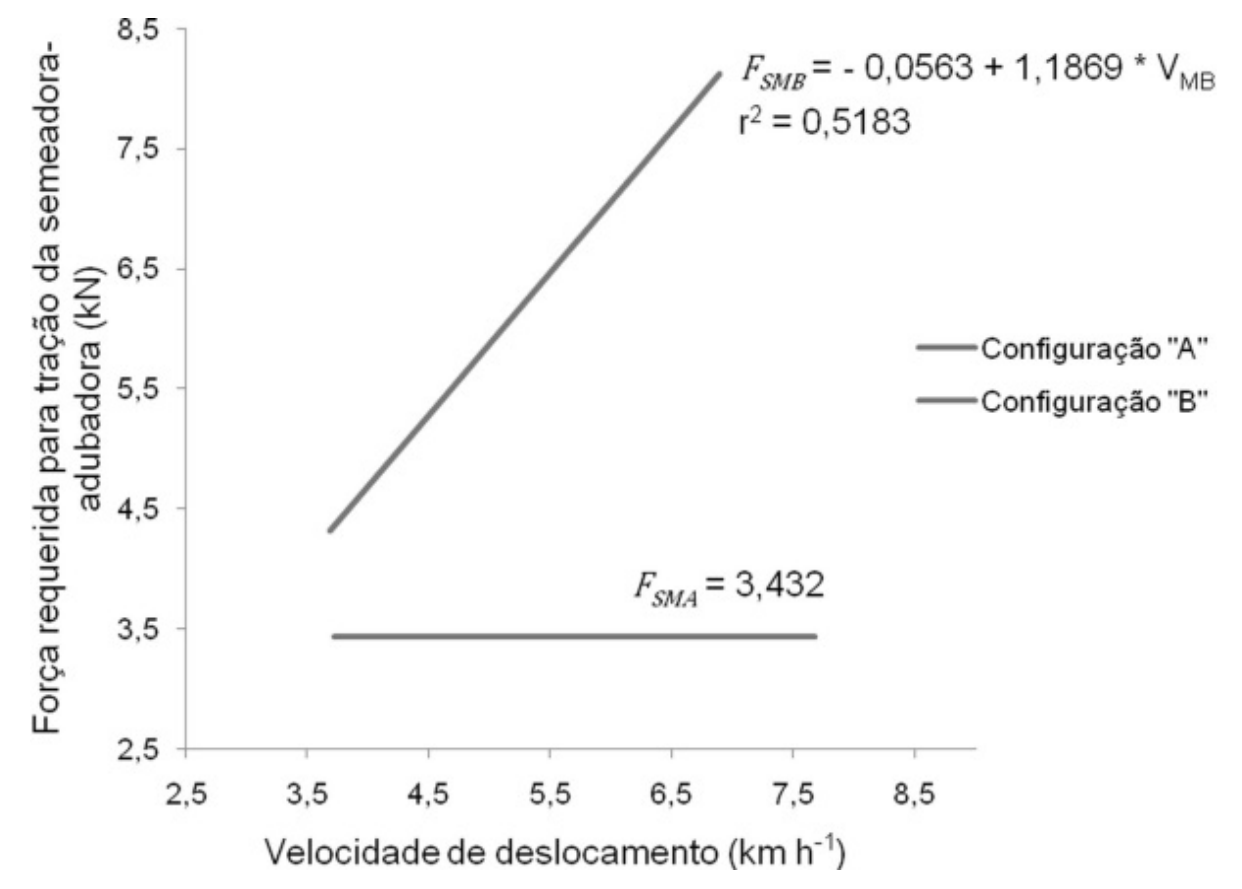

Figura 3. Estimativa da força requerida para tração da semeadora-adubadora em função da velocidade de deslocamento do conjunto mecanizado e das respectivas configurações de montagem da linha de plantio.

\section{REVENG}

143-153p.

ENGENHARIA NA AGRICULTURA, VIÇOSA - MG, V.23 N.2, MARÇO / ABRIL 2015 
que a exigência de força de tração é um parâmetro diretamente ligado ao tipo de mecanismo sulcador e à velocidade de deslocamento do conjunto mecanizado. Contudo, cabe destacar a forte influência exercida pelo mecanismo sulcador tipo facão e, principalmente, o efeito da interação deste com a velocidade de deslocamento sobre a força requerida para tração da semeadora-adubadora.

$\mathrm{O}$ efeito da velocidade de deslocamento sobre o requerimento de força de tração também não foi observado por Cortez et al. (2008) durante a avaliação do desempenho de um trator agrícola sob dois sistemas de preparo do solo (sistema plantio direto e convencional), juntamente com três marchas na operação de semeadura da Crotolaria juncea, as quais proporcionaram velocidades de $4 \mathrm{~km} \mathrm{~h}^{-1}, 5 \mathrm{~km} \mathrm{~h}^{-1}$ e $7 \mathrm{~km} \mathrm{~h}^{-1}$. No entanto, esses resultados, obtidos por Modolo et al. (2004) e Cortez et al. (2008), são semelhantes aos deste trabalho para a semeadora-adubadora, que estava montada com o mecanismo sulcador tipo disco duplo defasado (Configuração " $\mathrm{A}$ ") e operou em velocidades variando de $3,72 \mathrm{~km} \mathrm{~h}^{-1}$ a 7,68 $\mathrm{km} \mathrm{h}^{-1}$.

A potência requerida para tração da semeadoraadubadora foi influenciada pela velocidade de deslocamento do conjunto mecanizado, nas duas configurações de montagem da linha de plantio ("A" e "B").

A análise de regressão realizada com o propósito de determinar a influência da velocidade de deslocamento na variável em estudo, em ambas as configurações de montagem de linha de plantio, apresentou resultados significativos. Estes permitiram tal afirmativa e mostraram que o incremento da velocidade de deslocamento do conjunto mecanizado resultaram em um aumento proporcional na potência requerida para a tração da semeadora-adubadora.

Os modelos de regressão ajustados para essa variável apresentaram relacionamentos positivos com comportamentos não lineares, tipo potencial, crescentes com o aumento da velocidade de deslocamento do conjunto mecanizado e coeficientes de determinação $\left(\mathrm{R}^{2}\right)$ de 0,7473 e 0,7829, para as Configurações " $A$ " e "B", respectivamente. Esses modelos são representados pelas equações 6 e 7 .

$$
\begin{aligned}
& \mathrm{P}_{\mathrm{SMA}}=0,4421 \quad \mathrm{~V}_{\mathrm{MA}}^{1,42023} \\
& \mathrm{P}_{\mathrm{SMB}}=0,3556 \mathrm{~V}_{\mathrm{MB}}^{1,93657}
\end{aligned}
$$

em que,

$\mathrm{P}_{\mathrm{SMA}}=$ potência requerida para tração da semeadoraadubadora, na Configuração "A" $(\mathrm{kW})$; $\mathrm{V}_{\mathrm{MA}}=$ velocidade média de deslocamento do conjunto mecanizado, com a semeadora-adubadora montada na Configuração "A" $\left(\mathrm{km} \mathrm{h}^{-1}\right)$;

$\mathrm{P}_{\mathrm{SMB}}=$ potência requerida para tração da semeadoraadubadora, na Configuração "B" (kW); e

$\mathrm{V}_{\mathrm{MB}}=$ velocidade média de deslocamento do conjunto mecanizado, com a semeadora-adubadora montada na Configuração "B" $\left(\mathrm{km} \mathrm{h}^{-1}\right)$.

Os coeficientes de determinação $\left(\mathrm{R}^{2}\right)$ obtidos para os modelos de regressão ajustados para essa variável permitiram observar que $74,73 \%$ e $78,29 \%$ das variações ocorridas nas potências requeridas para tração da semeadora-adubadora equipada com mecanismos sulcadores tipo disco duplo defasado (Configuração "A”) e facão (Configuração "B”), respectivamente, puderam ser explicados pelas alterações nas velocidades de deslocamento do conjunto mecanizado.

Na Figura 4 é apresentado o comportamento da variável potência requerida para tração da semeadora-adubadora em função da velocidade de deslocamento do conjunto mecanizado com a semeadora-adubadora operando nas duas configurações de montagem da linha de plantio.

$\mathrm{Na}$ Figura 4, pode-se observar e confirmar o relacionamento positivo entre as variáveis e o comportamento não linear, tipo potencial, crescente, com incremento na potência requerida para tração da semeadora-adubadora, em decorrência de aumento na velocidade de deslocamento do conjunto mecanizado, para as duas configurações de montagem de linha de plantio.

Observou-se também, em velocidades de deslocamento idênticas, que os menores valores de potência estavam associados à Configuração " $\mathrm{A}$ ", indicando, para as condições experimentais, que a 


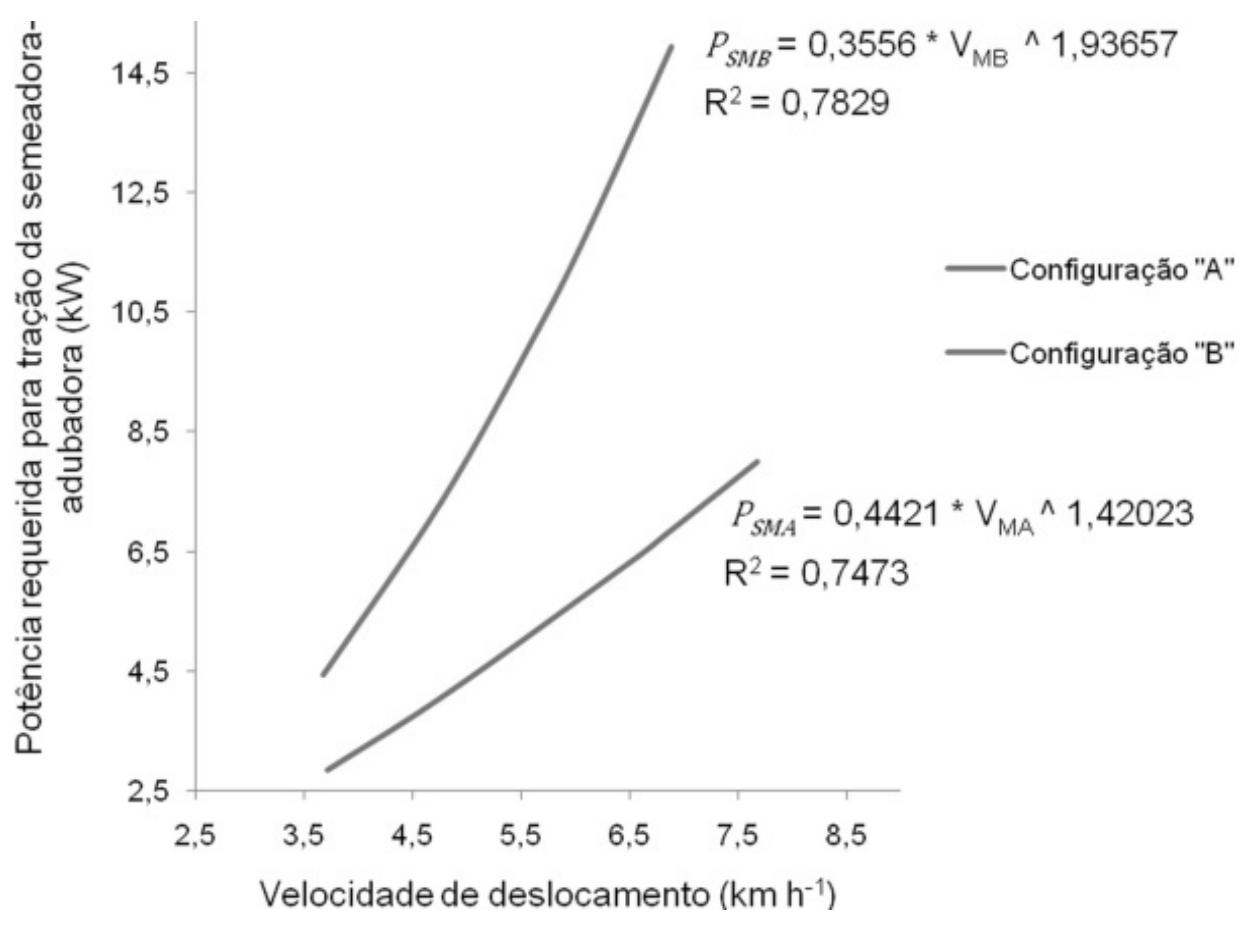

Figura 4. Estimativa da potência requerida para tração da semeadora-adubadora em função da velocidade de deslocamento do conjunto mecanizado e das respectivas configurações de montagem da linha de plantio.

configuração equipada com o mecanismo sulcador tipo disco duplo defasado no sistema de deposição de adubos demandou menor potência para tracionar a semeadora-adubadora que a Configuração "B", onde foi montado o mecanismo sulcador tipo facão.

Na Configuração "A", a menor velocidade de deslocamento do conjunto mecanizado $(3,72 \mathrm{~km}$ $\mathrm{h}^{-1}$ ) foi a que exigiu a menor potência para tração da semeadora-adubadora $(2,856 \mathrm{~kW})$ e a maior velocidade $\left(7,68 \mathrm{~km} \mathrm{~h}^{-1}\right)$, a que exigiu a maior potência $(7,997 \mathrm{~kW})$, resultando numa variação percentual de $180,0 \%$ para mais nos valores da variável dependente (potência requerida para tração da semeadora-adubadora).

$\mathrm{Na}$ Configuração "B", observou-se fato semelhante, pois a menor velocidade de deslocamento $\left(3,68 \mathrm{~km} \mathrm{~h}^{-1}\right)$ foi a que exigiu a menor potência $(4,434 \mathrm{~kW})$ e a maior velocidade $(6,89 \mathrm{~km}$ $\left.\mathrm{h}^{-1}\right)$ foi a que exigiu a maior potência $(14,936 \mathrm{~kW})$, resultando numa variação percentual de 236,9\% para mais nos valores da variável dependente (potência requerida para tração da semeadoraadubadora).

Observou-se, ainda, nas curvas geradas pelos modelos, que os efeitos da velocidade de deslocamento na potência requerida para tração da semeadora-adubadora ocorreram com taxas de crescimento distintas para as duas configurações de montagem de linha de plantio. A Configuração "A" obteve taxas de crescimento menores do que as obtidas pela Configuração "B", indicando que, nas condições experimentais, o incremento observado na potência em decorrência de aumento na velocidade foi menor na Configuração "A" do que na Configuração "B", ou seja, o incremento observado na variável potência correspondente ao aumento de $1,0 \mathrm{~km} \mathrm{~h}^{-1}$ na velocidade foi menor na Configuração "A" do que na "B".

Ao comparar os resultados obtidos das duas configurações de montagem da linha de plantio, observou-se que a configuração cujo mecanismo sulcador era do tipo facão requereu maior potência para tração da semeadora-adubadora que a configuração equipada com o disco duplo defasado, em todas as velocidades de deslocamento. Foram constatados aumentos de 58,5\% e 117,9\% na exigência de potência, quando a semeadoraadubadora deslocou nas velocidades de $3,72 \mathrm{~km}$

\section{REVENG 143-153p.}


$\mathrm{h}^{-1}$ e $6,89 \mathrm{~km} \mathrm{~h}^{-1}$, respectivamente. Esses aumentos evidenciaram que a exigência de potência para tração de semeadora-adubadora é um parâmetro diretamente ligado ao tipo de mecanismo sulcador e à velocidade de deslocamento do conjunto mecanizado.

Adicionalmente, observou-se pelas figuras e confirmou-se, por meio dos modelos de regressão ajustados para a variável em estudo que para as condições experimentais e velocidades de deslocamento de $4,0 \mathrm{~km} \mathrm{~h}^{-1}, 5,0 \mathrm{~km} \mathrm{~h}^{-1}$ e $6,0 \mathrm{~km}$ $\mathrm{h}^{-1}$, a potência requerida para tração da semeadoraadubadora equipada com mecanismo sulcador tipo facão (Configuração "B") era maior que a requerida para tração da semeadora-adubadora equipada com mecanismo sulcador tipo disco duplo defasado (Configuração "A"), em 64,6\%, 84,7\% e 102,9\%, respectivamente.

Estudos realizados por Silveira et al. (2013), com o objetivo de avaliar a demanda energética de um conjunto trator-semeadora-adubadora em sistema plantio direto, em função das velocidades de deslocamento e rotações no eixo do motor, na semeadura da cultura do milho mostraram que a demanda de potência é influenciada pela velocidade de deslocamento, corroborando o que foi observado neste trabalho. Esses autores verificaram que a cada unidade de variação na velocidade houve acréscimo de $0,68 \mathrm{~kW}$ na potência na barra por linha de semeadura. Os valores médios obtidos da variável em estudo foram de 2,32 kW, 2,67 kW, $3,69 \mathrm{~kW}$ e 4,72 kW por linha de semeadura, da menor para a maior velocidade $\left(3,5 \mathrm{~km} \mathrm{~h}^{-1}, 4,0\right.$ $\mathrm{km} \mathrm{h}^{-1}, 5,5 \mathrm{~km} \mathrm{~h}^{-1}$ e 7,0 $\mathrm{km} \mathrm{h}^{-1}$ ), representando um aumento de $104,74 \%$ quando a velocidade passou de $3,5 \mathrm{~km} \mathrm{~h}^{-1}$ para $7,0 \mathrm{~km} \mathrm{~h}^{-1}$.

Ao avaliar a potência requerida por semeadorasadubadoras equipadas com diferentes tipos de mecanismos sulcadores, em solo argiloso, Mahl et al. (2007) e Andreolla e Gabriel Filho (2010) constataram que as demandas de potência foram influenciadas pelo tipo de mecanismo sulcador e pela velocidade de deslocamento do conjunto mecanizado. Constataram ainda que, entre os tipos de sulcadores avaliados, o facão é o que exige a maior potência, em decorrência de sua maior profundidade de atuação e mobilização de solo, fato esperado e também observado neste trabalho.
Nos ensaios realizados com a semeadoraadubadora operando nas Configurações "A" e "B", não foram observadas influências da velocidade de deslocamento do conjunto mecanizado sobre a variável em estudo (patinagem das rodas motrizes do trator). Para essas configurações, os modelos de regressão mostraram-se não significativos $\mathrm{e}$, por essa razão, foram representados pelas equações das retas constituídas por constantes cujos valores corresponderam às médias aritméticas dos índices de patinagem das rodas motrizes do trator obtidos experimentalmente nas cinco velocidades de deslocamento do conjunto mecanizado.

As equações 8 e 9 representam os modelos de regressão obtidos para as Configurações " $A$ " e "B", respectivamente.

$$
\begin{aligned}
& \mathrm{P}_{\mathrm{TMA}}=0,0968 \\
& \mathrm{P}_{\mathrm{TMB}}=0,1190
\end{aligned}
$$

em que,

$\mathrm{P}_{\mathrm{TMA}}=$ patinagem das rodas motrizes, na Configuração "A" (decimal); e

$\mathrm{P}_{\mathrm{TMB}}=$ patinagem das rodas motrizes, na Configuração "B" (decimal).

$\mathrm{Na}$ Figura 5, mostra-se o comportamento da variável patinagem das rodas motrizes do trator em função da velocidade de deslocamento do conjunto mecanizado, com a linha de plantio da semeadoraadubadora montada nas Configurações "A" e "B". Durante os ensaios, observou-se comportamento semelhante para a patinagem das rodas motrizes posicionadas nos lados direito e esquerdo do trator.

Na Figura 5 e nas equações 8 e 9, constatouse que a variável patinagem das rodas motrizes do trator apresentou comportamento linear de valor constante para as duas configurações de montagem da linha de plantio (" $A$ " e "B"), sugerindo independência entre a variável em estudo e a velocidade de deslocamento do conjunto mecanizado.

Para as condições experimentais, esses resultados permitem afirmar que as velocidades de deslocamento compreendidas nos intervalos de $3,72 \mathrm{~km} \mathrm{~h}^{-1}$ a $7,68 \mathrm{~km} \mathrm{~h}^{-1}$ para a Configuração " $\mathrm{A}$ " e 


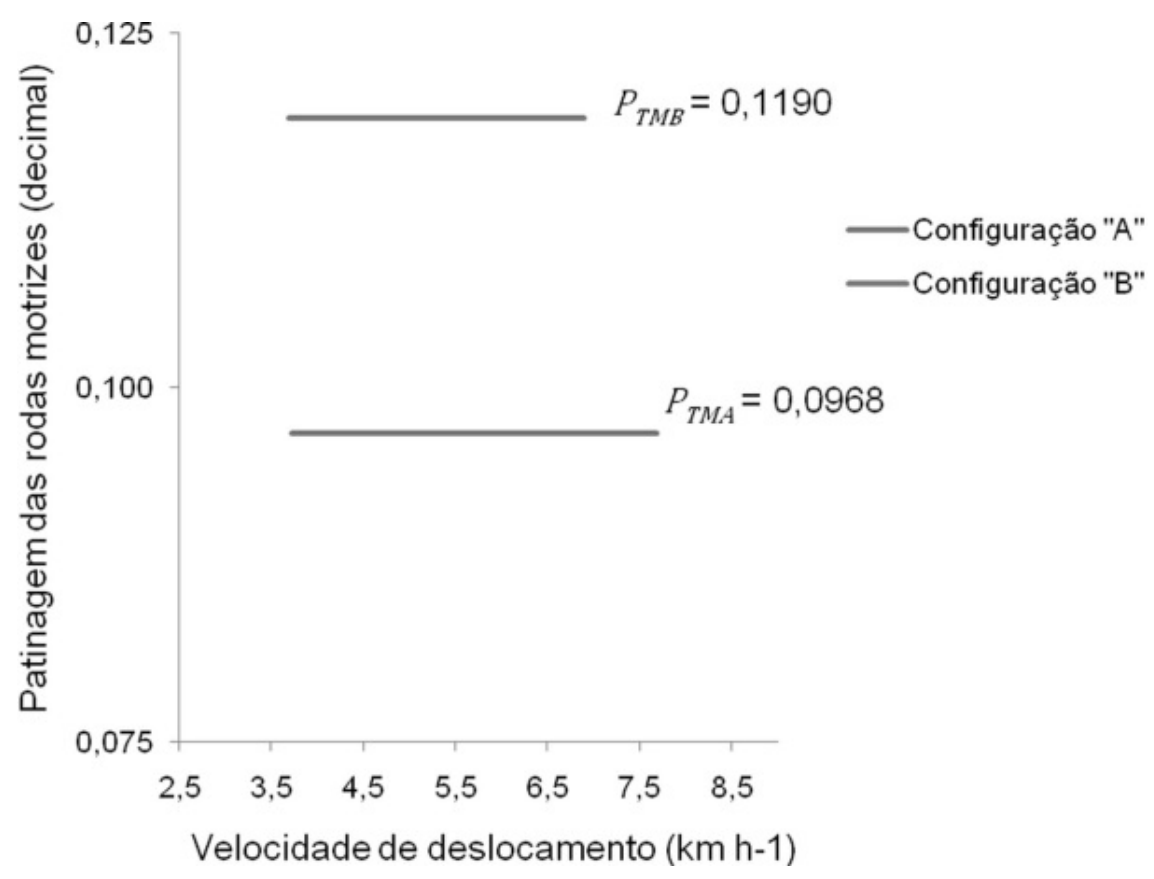

Figura 5. Estimativa da patinagem das rodas motrizes do trator em função da velocidade de deslocamento do conjunto mecanizado e das respectivas configurações de montagem da linha de plantio.

3,68 $\mathrm{km} \mathrm{h}^{-1}$ a 6,89 $\mathrm{km} \mathrm{h}^{-1}$ para a Configuração "B", não influenciaram na patinagem das rodas motrizes do trator. No entanto, observou-se que os valores da variável em estudo nas duas configurações de montagem da linha de plantio ("A" e "B") eram diferentes e o valor da Configuração "B" era maior que o obtido para a Configuração "A", indicando que, nas condições experimentais, as rodas motrizes do trator montado com a semeadoraadubadora, equipada com o mecanismo sulcador tipo facão, patinaram mais que as rodas motrizes do trator montado com a semeadora-adubadora equipada com o disco duplo defasado. Esse fato era esperado e pode ser explicado com base no maior requerimento de força de tração e potência apresentado pela semeadora-adubadora montada na Configuração "B", cujo mecanismo sulcador tipo facão atua em maior profundidade e mobiliza maior volume de solo.

Comparando os resultados deste trabalho com as recomendações da norma ASAE EP496.3 (ASABE, 2011), observou-se que o valor da patinagem apresentado pelas rodas motrizes da semeadora-adubadora montada na configuração “A” $(9,68 \%)$ está dentro dos padrões estabelecidos pela referida norma, enquanto o apresentado pela
Configuração "B" (11,90\%) não está. Para solo firme, o intervalo de patinagem recomendado pela referida norma técnica varia de $8,0 \%$ a $10,0 \%$.

\section{CONCLUSÃO}

- Para o modelo obtido na configuração com o mecanismo sulcador tipo facão, a variável força requerida para tração da semeadora-adubadora mostrou-se constante e independente da velocidade de deslocamento do conjunto mecanizado, já na demanda de potência, a configuração com discos defasados apresentou valores superiores ao mecanismo tipo facão em todas as velocidades e rotações do eixo do motor avaliadas.

\section{REFERÊNCIAS BIBLIOGRÁFICAS}

ANDREOLLA, V.R.M.; GABRIEL FILHO, A. Demanda de potência de uma semeadora com dois tipos de sulcadores em áreas compactadas pelo pisoteio de animais no sistema integração lavourapecuária. Engenharia Agrícola, Jaboticabal, SP, v.26, n.3, p.768-776, 2006.

\section{REVENG


ASABE - American Society of Agricultural and Biological Engineers. Agricultural machinery management. ASABE Standards 2011. St. Joseph, Michigan, 2011a. 7p. (ASAE EP496.3FEB2006 (R2011)).

ASABE - American Society of Agricultural and Biological Engineers. Soil cone penetrometer. ASABE Standards 2009. St. Joseph, Michigan, 2009. 3p. (ASAE S313.3FEB1999 (R2009)).

CORTEZ, J.W.; FURLANI, C.E.A.; SILVA, R.P.; GROTTA, D.C.C. Efeito residual do preparo do solo e velocidade de deslocamento na operação de semeadura da Crotalaria juncea. Scientia Agraria, Curitiba, PR, v.9, n.3, p.357-362, 2008.

EMBRAPA - Empresa Brasileira de Pesquisa Agropecuária. Manual de métodos de análise do solo. 2 ed. Rio de Janeiro, RJ: Centro Nacional de Pesquisa de Solo, 2011. 230p.

GABRIEL FILHO, A.; LANÇAS, K.P.; LEITE, F.; ACOSTA, J.J.B.; JESUINO, P.R. Desempenho de trator agrícola em três superfícies de solo e quatro velocidades de deslocamento. Revista Brasileira de Engenharia Agrícola e Ambiental, Campina Grande, PB, v.14, n.3, p.333-339, 2010.

LEVIEN, R.; FURLANI, C.E.A.; GAMERO, C.A.; CONTE, O.; CAVICHIOLI, F.A. Semeadura direta de milho com dois tipos de sulcadores de adubo, em nível e no sentido do declive do terreno. Ciência Rural, v.41, n.6, junho, 2011.

MAHL, D.; GAMERO, C.A.; BENEZ, S.H. Demanda energética de semeadora-adubadora de plantio direto em função de elementos de corte, velocidade e tipo de solo. Energia na Agricultura, Botucatu, SP, v.22, n.3, p.15-36, 2007.

MION, R.L.; BENEZ, S.H. Esforços em ferramentas rompedoras de solo de semeadoras de plantio direto. Ciência e Agrotecnologia, Lavras, MG, v.32, n.5, p.1594-1600, 2008.

MODOLO, A.J.; SILVA, S.L.; SILVEIRA, J.C.M.; MERCANTE, E. Avaliação do desempenho de duas semeadoras-adubadoras de precisão em diferentes velocidades. Engenharia na Agricultura, Viçosa, MG, v.12, n.4, p.298-306, 2004.

PALMA, M.A.Z.; VOLPATO, C.E.S.; BARBOSA, J.A.; SPAGNOLO, R.T.; MURILO MACHADO DE BARROS, M.M.; BOAS, L.A.V. Efeito da profundidade de trabalho das hastes sulcadoras de uma semeadora-adubadora na patinagem, na força de tração e no consumo de combustível de um trator agrícola. Ciência e Agrotecnologia, Lavras, v.34, n. 5, p.1320-1326, set./out., 2010.

SANTOS, A.P.; VOLPATO, C.E.S.; TOURINO, M.C.C. Desempenho de três semeadorasadubadoras de plantio direto para a cultura do milho. Ciência e Agrotecnologia, Lavras, v.32, n.2, p.540-546, mar./abr. 2008.

SILVEIRA, J.C.M; FERNANDES, H.C.; MODOLO, A.J.; SILVA, S.L.; TROGELlO, E. Demanda energética de uma semeadora-adubadora em diferentes velocidades de deslocamento e rotações do motor. Revisa Ciência Agronômica, Fortaleza, CE, v.44, n.1, p.44-52, 2013. 